\title{
A HISTÓRIA COMO MÚMIA: SOBRE A POESIA DE BRUNO TOLENTINO
}

\section{HISTORY LIKE A MUMMY: ABOUT THE POETRY OF BRUNO TOLENTINO}

RESUMO: Tendo passado boa parte de sua vida na Europa, Bruno Tolentino fez uma entrada tardia na poesia brasileira, no início dos anos 90, a tempo de envolver-se em polêmicas e de conquistar alguns prêmios literários, até seu desaparecimento, em 2007. Este artigo procura associar, ao conteúdo polêmico das propostas de Tolentino, a leitura de seu último livro de poemas, $A$ imitação do amanhecer (2006). Ao relacionar oaspecto especulativo às opções formais desse conjunto de textos, o ensaio procura evidenciar os dilemas com os quais se envolveu o projeto poético de Tolentino, os caminhos que poderia ter aberto e os bloqueios que o limitaram.

PALAVRAS-CHAVE: Bruno Tolentino; poesia contemporânea; anacronismo; crise.

ABSTRACT: Having spent the greater part of his life in Europe, Bruno Tolentino made a late entrance into the Brazilian poetry, in the early 90s, in time for engaging in polemic arguments

\footnotetext{
${ }^{1}$ Departamento de Teoria Literária, Instituto de Estudos da Linguagem, IEL, Universidade Estadual de Campinas, UNICAMP, CEP 13083-859, Campinas, Estado de São Paulo, Brasil. E-mail: siscar@iel.unicamp.br
} 
and for winning some literary prizes, until his disappearance, in 2007. This essay tries to associate the controversial content of proposals of Tolentino with the reading of his latest book of poems, The Imitation of Dawn (2006). By relating the speculative aspect to formal options of thesepoems, this text intends to show the dilemmas in which the poetic project of this author was involved, the paths he could have opened and the blockages that confined him.

KEYWORDS: Bruno Tolentino; contemporary poetry; anachronism; crisis.

Bruno Tolentino costumava reclamar que seus críticos não liam o que escrevia, baseando-se apenas em sua "fama". Seria uma experiência provavelmente reveladora chegar a seus textos sem o preconceito e sem o beneplácito que lhe conferem a trama atípica de sua biografia, os nomes próprios que povoavam seu discurso autobiográfico, as narrativas sobre a concepção de seus textos ou, ainda, a sempre generosa contracapa de seus livros; isto é, sem a consideração de seu renome e de sua situação pública. Nesta ordem de leitura, baseada tanto na isenção quanto num certo idealismo poético, intentaríamos ler seus textos sem as expectativas criadas pelas polêmicas que instaurou e pelas cáusticas opiniões que exprimia sobre a (falta de) inteligência local, na sua meteórica passagem pelo cenário poético brasileiro.

Entretanto, a julgar justamente pela natureza dessa fama e das declarações públicas que a sustentaram, poderíamos dizer que o autor colaborou bastante para que seu trabalho fosse lido para além daquilo que vale, digamos, intrinsecamente. Sua atividade pública foi frequentemente destinada a criar estratégias de recepção e referenciais de política literária, e não apenas a produzir poemas ou estudos sobre literatura. Assim como o discurso de seus desafetos concretistas, o de Tolentino, 
de modo ainda mais ostensivo, procura impor-se pela abordagem contundente da situação brasileira e legitimar-se pela presunção deproximidade pessoalcom grandes nomes da poesia e da crítica internacional, cujos comentários supostamente lhe confeririam autoridade. Frases de Yves Bonnefoy, de Jean Starobinski e de Saint-Jean Perse, por exemplo, vêm frequentemente dar lustro e moldura à sua entrada tardia na vida literária brasileira, onde era praticamente desconhecido.

Não se trata de questionar o valor da estratégia, aliás, compreensível como tentativa de recuperar o "tempo perdido", dada sua situação de poeta apátrida; lembre-se que, antes de As horas de Katharina (1994), que marca seu retorno à vida literária brasileira (praticamente, sua estreia na poesia em língua portuguesa, excetuado um livro de juventude), o poeta havia publicado, desde os anos 1970, até aquela data, livros em língua francesa e em língua inglesa. Mas constata-se, sem muita dificuldade, que operações de autolegitimação acompanharam de muito perto, e desde o início, a apresentação que fez, ao público, de seus poemas.

A essa constatação, eu acrescentaria apenas a seguinte indagação metodológica: como evitar que isso ocorra, isto é, que a obra ganhe sentido de acordo com a coerência e com os conflitos que ela estabelece em relação à situação pública da fala do poeta, formalizada em diferentes gêneros (poemas, ensaios, artigos de jornal, entrevistas, correspondência) e em diferentes tons (polêmico, reservado, ambicioso, modesto)? Como evitar, inclusive, que venha a se somar a esse conjunto sua fortuna crítica (jornalística ou universitária), que colabora decisivamente para "colar" à obra determinados sentidos, que o próprio poeta não pode mais desconsiderar?Trata-se, a meu ver, de uma dimensão importante para a compreensão de uma obra literária, quando conseguimos fazer dessa marginália parte do objeto a ser analisado, e não simplesmente o conjunto de acessórios que o confirmam ou o agravam. Por isso mesmo, creio que não há porque lamentar que a obra seja suscetível de filtragem por parte de outras estratégias discursivas e de política literária. No caso de Tolentino, e de modo 
exemplar, o mais provável é que a necessidade de pleitear o benefício da objetividade seja por si mesma parte da questão.

Nesse sentido, creio que o essencial daquilo que caracteriza o acontecimento da obra de Tolentino para a poesia brasileira não são as razões que ele próprio levanta para promover-se ou defender-se; nem meramente o histrionismo e o anacronismo que lhe imputam seus críticos. Seus livros não deveriam ser retirados do contexto discursivo em que aparecem; muito pelo contrário, ganhariam sendo compreendidos a partir dele, por meio de uma reflexão exigente que leve em conta tanto suas legítimas críticas culturais quanto suas limitações e suas contradições. Certamente, esse conjunto de textos e discursos poderiam ser lidos com maior profundidade ao serem retirados da lógica mundana dos prêmios literários e da fogueira das vaidades, assim como dos paradigmas congelados de história literária, que alimentam processos sumários de promoção ou de condenação. Precisariam, em suma, ser colocados à prova daquilo que eles próprios buscam, provocam ou desafiam.

Esses protocolos críticos me levam a abordar o último livro de poemas de Bruno Tolentino, de modo preliminar, tendo a clareza de que uma leitura mais detalhada e mais rigorosademandaria esforços mais alentados que os de um artigo, a fim de levar em conta ainda mais decisivamente o corpus textual do autor.

Em A imitação do amanhecer, livro de poemas publicado em 2006, a poesia de corte clássico e de dicção alta são opções que encontram ecos em posições conhecidas de Bruno Tolentino, na perspectiva da rejeição dos valores da novidade e da popularidade, daquilo que seria percebido como o "aqui-agora" da poesia. Como se respondesse a esses valores e, por meio deles, associasse sua escrita a vários episódios de sua militância crítica, o livro retoma a figura do espaço exótico, da cidade de exílio. Além de ter vinculação com a biografia pregressa do poeta, inclusive com sua experiência carcerária, a cidade distante, emblema do lugar para o qual se foge, é uma figura clássica da tradição poética. Em $A$ imitação do amanhecer, essa cidade é Alexandria, nome de antigo pres- 
tígio, o que coloca em relação bastante estreita o deslocamento espacial do distante com aquilo que seria outro tipo de evasão, o deslocamento no tempo, representado pelo antigo, pelo ancestral, aspecto explorado em outros textos.

Composto de quantidade considerável de 538 sonetos-estrofes, o livro é dividido em três longos movimentos, inspirados pela estrutura da sonata, misturando solenes meditações sobre a transcendência com vibrantes experiências amorosas e prosaicas. Por isso, o que mais se destaca no conjunto é esse descompasso formal e histórico-filosófico. Há muito tempo, a separação entre real e ideal foi arrasada pela secularização, o que faz com que a especulação sobre suas correspondências ou dissonâncias tenha o aspecto de ingenuidade ou de embuste elegante, sobretudo nos termos já calejados de um platonismo didático e recheado de fórmulas, como é o caso. 0 mesmo se pode dizer sobre o aspecto formal mais evidente do livro, uma vez que a forma fixa, depois de um século de vanguardas, tornou-se emblema daquilo que pode haver de menos poético em poesia. Percebida a obra dessa maneira, o leitor poderia enfadar-se com razão e pensar: eis mais um nostálgico, para quem a conservação é o telos.

Mas não é bem o caso. 0 que realmente chama a atenção no livro é a presença (de outro modo corriqueira) do prosaico e do decrépito contracenando de modo discrepante com a recuperação do sublime tradicional, traço de estilo já destacado pela recepção de Tolentino (cf. PÉCORA, 2003), quer para caracterizar um charme provocativo, quer para lamentar-lhe a imperícia. Para entender o que está em jogo, é preciso lembrar o quanto a Alexandria de Tolentino nos remete ao Douve, de Yves Bonnefoy, ou ainda, antes deste, a Bizâncio, de Yeats, ou à Citera, de Baudelaire, entre muitas outras figurações relacionadas ao paradisíaco que, aliás, transbordam amplamente o âmbito da poesia moderna. Mas, se a Bizâncio do poema de Yeats ("Sailing to Byzantium") é um artifício de eternidade capaz de fazer face à decrepitude do real, a Ale- 
xandria de Tolentinoé a própria realidade decrépita, urinol manchado pelos respingos do sol platônico.

A princípio, portanto, temos a impressão de que a utopia artística segundo a qual a arte poderia melhorar o mundo - ou pelo menos criar um "paraíso artificial" (BAUDELAIRE) a partir do qual a vida pudesse tornar-se suportável - é substituída, no caso de Tolentino, pela evidência da condição radicalmente degradada, do simulacro como condição de realidade. Muitos poetas modernos preferiram essa solução, evitando idealismos ou inocências sublimadoras ou compensatórias, dentro dos quais a postulação do sublime ou da soberania do sujeito seria apenas a ponta mais saliente. Tampouco faltaram aqueles para quem o sublime permanece uma questão modulada pela experiência da queda, que poderia ser nomeada, de modo mais amplo, uma experiência de crise. A degradação, aliás, seria uma imagem possível para a própria poesia da modernidade. Ocorre que, em Tolentino, especificamente, isso não impede que o poeta continue a enxergar, na decrepitude generalizada, os sinais de sua própria magnificência, a promessa divina cumprida por meio de sua arte, reciclando, em proveito próprio, os esquemas mais duvidosos do discurso artístico e religioso, como o da graça e o da revelação, antes de qualquer elaboração ou profanação da mística tradicional. É possível dizer que a dor do exilado e a alegria atroz do iluminado tiram, aqui, proveito uma da outra, revelando a cumplicidade entre a reivindicação de soberania e a ideia convencional do sacrifício. Como se, pelo fato de sofrer (isto é, de viver na decrepitude, "encharcado" pelos respingos da transcendência aviltada, "como se o próprio sol encharcasse-me" [TOLENTINO, 2006, p.57]), o sujeito fizesse jus à graça ou ao lucro do paraíso da revelação artística.

Chega a ser grotesca a naturalidade e a franqueza com que o poeta tenta manipular - e, portanto, corrigir - a seu favor esse paradoxo fundador da modernidade poética, que identifica, na sua própria crise, a emergência de um modo específico de ver o mundo. Pois, se a poesia moderna tira grandeza do abalo da situação pessoal ou pública do poe- 
ta, isso pode ser verificado apenas como consequência histórica indireta e a posteriori de sua experiência da crise. Trata-se de um paradigma verificável em grande parte do repertório da alta modernidade, com a qual dialoga o próprio Tolentino. Com a diferença, portanto, de que o paradoxo da crise, no caso do poeta brasileiro, parece dissolver-se no esplendor de si mesmo como poeta. Se a solução poética em questão parece tão pouco verossímil não é porque nosso tempo já não a permitiria, por anacronismo (segundo o argumento mais corrente); também não se explica exatamente pelo desinteresse da discussão que ressurge com o projeto: são duas objeções igualmente curtas e problemáticas, que ilustram - mais do que explicam - o problema em questão.

Creio que a solução de $A$ imitação do amanhecer não é verossímil porque os meios colocados à disposição não estão à altura da tarefa. Ao recusar aliberdade formal característica da modernidade - baseada na ideia de que a forma é única e deve ter relação com a experiência, e não com a convenção, poética - Tolentino não se enquadra perfeitamente na categoria do mero conservador. Se não concebe a forma como uma elaboração do real, a ser transformada em história, também não se baseia exatamente na ideia da manutenção de determinada tradição. A atitude do poeta pretende ser ativa e não meramente reprodutiva; não se define pela proposta de continuar a tradição. Sua atitude é questionadora, reivindicatória e, finalmente, irônica. A deficiência de meios a que me refiro tem a ver com o fato de que essa atitude, para realizar-se, deve empobrecer violentamente a ideia de tradição, limitando-a a seus moldes vulgarizados e a seu gosto pela excepcionalidade - confirmando-a, portanto, indiretamente naquilo que ela tem de mais gasto. Em outras palavras, no que diz respeito à solução poética dada ao diálogo com a historicidade das formas e das ideias, a contrariedade que o poeta estampa na superfície provocativa do gesto, ao invés de produzir um abalo na nossa visão dos modelos, acaba assumindo rapidamente a condição de um desejo de contrarreforma no âmbito da modernidade. Trata-se, afinal, de uma tentativa de retorno, e não exatamente de conservação ou de refundação. 
Para colocar a questão de outro modo, seria interessante lembrar que a ideia moderna do poema, na esteira do impulso anticlássico do romantismo, se apropriou da forma como uma espécie de experimento relacionado à singularidade e, a partir daí (graças a uma leitura parcial das formulações baudelairianas sobre o assunto), como inscrição que mimetiza a contingência e a transitoriedade do tempo presente. Não é difícil perceber que essa aventura da forma foi muitas vezes contestada pelo retorno da forma fixa, mas também enfraquecida pelo cabresto do determinismo histórico que fez com que a escolha dos materiais do poema tenha sido subordinada, frequentemente, à atualidade cultural ou econômica, como se coubesse à poesia ecoar a lógica de sua época, como se tivesse necessidade de dizer-lhe respeito por oposição ou mimetismo. É o que fica mais evidente nos projetos de vanguarda, que se valem invariavelmente do paralelo e da sintonia com o presente, de diversas maneiras, fazendo com que a aventura da forma seja traída pelo impulso mimético de atualização, de destruição, tornando, ao longo do tempo, um gesto "tradicional" (segundo o paradoxo da "tradição da ruptura" formulado por Octavio Paz (2013).

Considerando-se exclusivamente $A$ imitação do amanhecer - livro representativo da curta bibliografia de Tolentino, escrito durante 25 anos (de 1979 a 2004) - seríamos tentados a concluir que o projeto do poeta esbarra em simplificações que só se justificam na perspectiva de um ressentimento histórico que, a propósito da oposição às vanguardas e ao hibridismo, acaba nos propondo uma visão bastante restrita daquilo que merece ser recebido (ou conquistado) como herança. Basicamente, Tolentino parece confundir o soneto com a tradição, o erudito com o culto, o clássico com o universal, o preciosismo (rima rica, referências mitológicas, métrica clássica francesa) com a preciosidade.

Ora, o soneto não deixa de ter sua atualidade. No Brasil, práticas tão diferentes quanto as de Glauco Mattoso ou de Paulo Henriques Britto seriam suficientes para ilustrá-lo. Jacques Roubaud, na França, poeta conhecido pela experimentação - que revisita o soneto há décadas, ten- 
do escrito uma tese de doutorado sobre o assunto -, chegou a declarar, certa vez, que todo poema é um soneto, qualquer que seja seu formato. Uma formulação deste tipo teria consequências interessantes para uma releitura da tradição, uma vez que nos levaria a repensar toda a problemática (por exemplo, formal) do soneto como uma espécie de diminutivo metafórico das questões da poesia. Conhecemos também outros tipos de relação com a forma fixa, que recuperam a forma tradicional para relê-la, questioná-la, matizá-la com elementos heterogêneos à sua lógica ou simplesmente para desautorizá-la parodicamente. Comparada a esses projetos, a defesa do prestígio do soneto garantido pela aura tradicional dos quatorze versos beira a devoção ou o fetichismo; a não ser que adotemos a mesma posição discursiva (de adesão ou de crença), não há como ver a operação senão como um passe de mágica que criaria a ilusão do prestígio ou do sagrado para poder colocar-se mais facilmente como seu beneficiário ou como seu sacerdote.

0 autor, que não vê poesia senão no "mimetismo", segundo palavra do livro, imola assim a aventura da experimentação. Dito de modo mais próximo à questão estética, acredita que o prodígio da arte só pode se realizar na esfera do equívoco ou do simulacro de realidade, nesta prisão que é o real. Os poemas de $A$ imitação do amanhecer estão repletos das imagens do encarceramento ("gaiola”, “calabouço", "cárcere”), que são mais do que simplesmente uma referência autobiográfica. A imagética do aprisionamento é, aqui, exemplarmente fixada e reaparece em outros textos (como em As horas de Katharina, na figura da cela conventual e do exílio no "castelo interior"). Ela é alçada à condição de recurso poético e especulativo (ao serassociada, por exemplo, à ideia da alma "enjaulada", paradigma platônico[TOLENTINO, 1994, p.28]). A Alexandria que lhe agita o sangue está aprisionada pelo sensível, assim como a experiência é prisioneira da forma (que lhe serve de fôrma ou de formato). À dispersão do sentido, Tolentino prefere a redoma do soneto como oco do qual não se pode escapar e cujo paroxismo "infecundo" consiste em gozar estando preso. Pois, se a lição sobre o real e o ideal é platônica, 
a formulação do prodígio da arte vem por conta do poeta. Sua dita "jovialidade" se manifesta nessa operação pela qual o poeta transforma em "visão" e em graça o paradoxo, infelizmente destituído de ironia, de uma suposta "lição de liberdade": "[...] se a arte é um calabouço, / essa visão é uma lição de liberdade" (TOLENTINO, 2006, p.33).

Em suma, é possível perceber como Tolentino trafega pelos grandes paradigmas da poesia e da arte, articulando à sua maneira um modo de relação com a história que não prescinde nem do idealismo (uma vez que precisa da ideia de mimetismo para justificar o seu recurso à forma, praticada como formato) nem da historicidade (vivida como transformação do degradado em prodígio do próprio gozo). A contradição não é apenas sofrida sintomaticamente pelo poeta, porém sistematicamente escamoteada a fim de mistificar o modelo e de legitimar o gozo. Por isso, infelizmente, o que poderia haver de estimulante no projeto acaba suplantado pelo seu próprio desejo de perversão eficiente.

Não há como não lamentar que o tipo de questão colocado pelo autor não tenha lhe incitado a discussões históricas mais consequentes, mais exigentes. Infelizmente, o modo como sua "fama" se constituiu pode ter colaborado para essa deficiência, dificultando em muito o viés reflexivo. Poderíamos esperar desse poeta uma crítica organizada da ideologia de vanguarda, que desenhou de maneira vigorosa a história da poesia no século XX, sem deixar de operar exclusões injustificadas e de gerar alguns vícios que acabaram se naturalizando como sinônimo da própria poesia. Tolentino estava em posição de fazê-lo, ao alinhar-se à grande tradição europeia (Yeats, Caváfis, Saint-John Perse). Porém, menos do que tornar sensíveis as diferentes temporalidades históricas, menos do que se explicar com o prisma órfico que poderia sustentartal crítica, o poeta contentou-se frequentemente com julgamentos sumários de valor histórico contestável e como "órfico de pensar em quatorze versos", como diz em Os sapos de ontem (TOLENTINO, 1995).

Do mesmo modo, passando ao campo da poesia no Brasil, poderíamos imaginar uma proposta de revisão dos valores estabelecidos pela 
tradição vitoriosa do Modernismo brasileiro e das vanguardas experimentais de meados do século. As continuidades e os deslocamentos desses valores certamente ajudariam a esclarecer diversos tipos de exclusões e expectativas, que nos definem ainda hoje em relação à concepção de forma e à função do poeta ou do poema. Em outras palavras, bem peneiradas, as afirmações peremptórias de Tolentino contêm proposições que mereceriam atenção do ponto de vista histórico-crítico. Entretanto, ao invés disso, apresentam-se permanentemente ameaçadas pelo devaneio de grandeza. Ao invés de nos ajudar a entender os deslocamentos da ideologia de vanguarda, Tolentino acaba por inserir-se no campo da polarização entre o fim do verso e a restauração da forma fixa, entre a ilusão de simplicidade e a duvidosa impostação (chamada por ele de "clássica"), entre o telos da tecnologia e uma história "embalsamada", entendida como repetição degradante. Daí que a "imitação do amanhecer" inscrita no título do livro de poemas, ainda que carregue a ambição órfica de fazer a luz, limita-se a deliciar-se na prisão da poesia como "mimetismo", ou repetição mumificante.

Essa prisão se manifesta como visão de história literária também no momento em que Tolentino nega qualquer vitalidade à tradição poética brasileira (excetuados casos pontuais). A esse propósito, o poeta se defronta diretamente com a crítica brasileira, por exemplo, a uspiana (ou, mais precisamente, determinada geração de críticos uspianos). E não é sem razão, uma vez que um de seus interesses dessa crítica é o de ilustrar, organizar e aprofundar o legado modernista, entendido a partir da ideologia de vanguarda, de pesquisa estética e atualização nacional. A Tolentino, parece conveniente uma solução oposta: guardando como aliados alguns ícones da poesia do século XX (Bandeira, Cecília Meireles, Drummond), considera a vanguarda uma "farsa" (TOLENTINO, 1995), procurando apagar o passado naquilo que ele tem de marcadamente experimental e comprometido; seu propósito, de fato, é o de excluir qualquer outro imperativo que não seja o da tarefa órfica do poeta, sua capacidade de manter “a possibilidade da língua” (JABOR, 1994). Há, en- 
tretanto, entre esses pontos de vista críticos, um ponto de encontro não explicitado: ambos empreendem um esvaziamento do contemporâneo, quer seja como posteridade enfraquecida ou deserdada dos monumentos modernistas, quer seja como evidência da marginalidade cultural dentro da qual tais monumentos constituem exceções (vivemos, segundo Tolentino, à sombra do "circo tropical" do concretismo[cf. JABOR, 1994]). Por isso, é necessário avaliar também as estratégias de inserção (crítica num caso, poética no outro) que impõem como informação aquilo que, no fundo, são também desdobramentos de determinados desejos de negação ou de frustração da continuidade.

Um artigo de Arnaldo Jabor, publicado em 1994, no momento da volta de Tolentino ao Brasil, reitera os termos desse esvaziamento do presente, ainda que o identifique mais restritamente ao fim de uma época, iniciada pouco antes do golpe militar. Relatando conversa telefônica, Jabor cita o poeta:

Bruno me diz ao telefone: 'Vim preencher um vazio na poe-
sia brasileira. Há um vazio que só a retomada clássica de uma
poesia de ideias poderá preencher. [...]"'. Em seguida, o articu-
lista reitera esse julgamento, por conta própria: "Tudo foi co-
municado. Talvez agora precisemos do claro segredo clássico
da língua. Começar um novo estoque - estamos sem estoque.
Talvez Bruno Tolentino venha a ajudar a renovar nossa reserva
de grãos (JABOR, 1994, s.p.).

Percebemos como a ideia de vazio se impõe como pressuposto que sustenta o argumento (ou a retórica) do preenchimento, no caso de Tolentino, possível graças ao estofo de uma "poesia de ideias" (expressão no mínimo problemática, em termos de definição de poesia), a ser "retomada" de um passado identificado com a tonalidade "clássica". É como preenchimento de um vazio que sua poesia pretende ser necessária, ou contemporânea. A descrição de Jabor, embora se valha de elementos da própria vanguarda ("tudo foi comunicado", fim de uma época, etc.), acredita reiterar o diagnóstico do vazio, associando-o à necessidade da 
"reserva", da provisão, da poupança, do acúmulo de possibilidades (de "grãos"). A posição é reconhecível, dentro da narrativa de rupturas que pensa o contemporâneo como época pós-vanguardista, ou "pós-utópica" (segundo a expressão de Haroldo de Campos). E a conclusão tem sintonia com a moralidade pluralista dessa pós-utopia: se precisamos de estoques, por que não do "claro segredo clássico"? por que não isso, entre outras coisas? ou, talvez mais precisamente: por que não o "claro segredo clássico da língua", para começar, a fim de limpar o depósito no qual faremos novos estoques? Encarar a "retomada clássica" como uma alternativa entre outras, ou como alternativa de "grau zero", é um modo de desistoricizar violentamente as formas e as ideias. São posições como esta que abriram espaço para que retornos e arcaísmos fizessem aparição, desde então, na poesia brasileira, de forma mais ou menos fecunda (basta pensar nos diferentes tratamentos da questão de Hilda Hilst a Bruno Tolentino, ou de Paulo Henriques Britto a Alexei Bueno, por exemplo); mas, ao permitir sua emergência, bloquearam, igualmente, qualquer reflexão mais consequente sobre seu sentido, sobre os ossos da história que preferimos ocultar.

É preciso dar seriamente razão a Bruno Tolentino, quando, com ironia um tanto perversa, constata que, debaixo do corpo mumificado da história, reencontram-se a dor e a graça de seus ossos:

\footnotetext{
Mandei embalsamar para sempre uma praça e a Musa diligente obedeceu-me - ele e Alexandria juntos vão arrancando a pele àquela múmia de escultura, e dói-me ver-lhe os ossos outra vez, ah, tão cheios de graça! (TOLENTINO, 2006, p. 299)
}

\section{REFERÊNCIAS}

JABOR, A. "Tolentino traz de volta a peste clássica", Folha de São Paulo, Caderno Ilustrada, 19 de julho de 1994. 
PAZ, O. Os filhos do barro. Tradução: Ari Roitmane Paulina Wacht. São Paulo: Cosac\&Naify, 2013.

PÉCORA, A. Gesto besta, sublime intangível.Folha de S. Paulo,Caderno Mais!, 11 de maio de 2003.

TOlEnTino, B. As horas de Katharina. São Paulo: Cia. das Letras, 1994.

. "A farsa como história”, prólogo de Os sapos de ontem (Rio de Janeiro: Diadorim, 1995). Disponível em: http://blog.karaloka.net/ wp-content/uploads/2006/04/sapos_tolentino.pdf Acesso em: 22 de janeiro de 2013.

.A imitação do amanhecer. Rio de Janeiro: Editora Globo, 2006. 